\title{
The Whys and Wherefores of Antibiotic Resistance
}

\author{
Cameron R. Strachan ${ }^{1}$ and Julian Davies ${ }^{2}$ \\ ${ }^{1}$ MetaMixis Biologics, Vancouver, BC V6T 1Z3, Canada \\ ${ }^{2}$ Department of Microbiology and Immunology, University of British Columbia, Vancouver, BC V6T 1Z3, \\ Canada \\ Correspondence: jed@interchange.ubc.ca
}

\begin{abstract}
The development and rapid dissemination of antibiotic-resistant bacterial pathogens has tarnished the dream of a world without infectious diseases. However, our understanding of these processes, paired with sequence information from terrestrial bacterial populations, indicates that there is no shortage of novel natural products that could be developed into new medicines. Regardless, their therapeutic success in the clinic will depend on the introduction of mandatory controls and use restrictions.
\end{abstract}

One solution to control the threat of antimicrobial resistance is scientific discovery.

—Dame Sally Davies

$T^{1}$ he history of man has been punctuated by many plagues and pestilences during existence on this planet (see Table 1 for a partial list). In certain instances, upward of $50 \%$ of the population of a city or a country may have perished while others survived, albeit seriously weakened. Plagues have shaped history at both local and worldwide levels from an economic point of view by crippling the workforce, and also from a military viewpoint, infections on one side in a conflict could lead to victory over the enemy. In recent times, the most devastating microbial infection was the Spanish flu pandemic in 1918-1920 that killed some 5\% of the world's population. However, in the past 50 years, the world has seen the rapid evolution of a new plague - that of worldwide antibioticresistant (AR) microbes. Although not a disease in itself, AR results from the failure to effectively prevent and treat many diseases, leading to widespread untreatable microbial infections and greatly increased morbidity and mortality: a plague of resistance genes (Davies and Davies 2010). AR transforms treatable infectious diseases into untreatable ones. Regrettably, we were warned and aware of the cause and consequences of AR development and dissemination in the 1960s, but nonetheless we let it happen!

Bacterial pathogens readily develop resistance on treatment with antibiotics; they are often caused by the results of mutation of specific target genes but primarily by the inheritance of plasmids carrying resistance gene clusters (Wright 2011). Multidrug-resistant pathogens have been clinically relevant since the 1950s and can be considered the leading cause of mortality worldwide since the introduction of antibiotics (Davies and Smith 1978). Currently, estimates indicate that upward of 10 million

Editors: Lynn L. Silver and Karen Bush

Additional Perspectives on Antibiotics and Antibiotic Resistance available at www.perspectivesinmedicine.org

Copyright (C) 2017 Cold Spring Harbor Laboratory Press; all rights reserved; doi: 10.1101/cshperspect.a025171 Cite this article as Cold Spring Harb Perspect Med 2017;7:a025171 
C.R. Strachan and J. Davies

Table 1. History of plagues

\begin{tabular}{|c|c|c|c|c|}
\hline $\begin{array}{l}\text { Death toll } \\
\text { (estimate) }\end{array}$ & Location & Date & Comment & Disease \\
\hline $\begin{array}{l}\text { ca. } 40 \% \text { of } \\
\text { population }\end{array}$ & Europe & $541-542$ & $\begin{array}{l}\text { Plague of Justinian, attributable to the } \\
\text { name of the Byzantine emperor in } \\
\text { power at the time }\end{array}$ & Bubonic plague \\
\hline $\begin{array}{c}30 \% \text { to } 70 \% \text { of } \\
\text { population }\end{array}$ & Europe & $1346-1350$ & $\begin{array}{l}\text { "Black Death" or second plague } \\
\text { pandemic, first return of the plague } \\
\text { to Europe after the Justinianic plague } \\
\text { of the 6th century }\end{array}$ & Plague \\
\hline 100,000 & England & $1665-1666$ & Great plague of London & Plague \\
\hline 76,000 & Austria & 1679 & Great plague of Vienna & Plague \\
\hline$>50,000$ & Russia & $1770-1772$ & Russian plague of $1770-1772$ & Plague \\
\hline$>>100,000$ & Asia, Europe & $1816-1826$ & First cholera pandemic & Cholera \\
\hline$>>100,000$ & $\begin{array}{l}\text { Asia, Europe, } \\
\text { North } \\
\text { America }\end{array}$ & $1829-1851$ & Second cholera pandemic & Cholera \\
\hline $20,000+$ & Canada & $1847-1848$ & Typhus epidemic of 1847 & Epidemic typhus \\
\hline $1,000,000$ & Russia & $1852-1860$ & Third cholera pandemic & Cholera \\
\hline $1,000,000$ & Worldwide & $1889-1890$ & 1889-1890 flu pandemic & Influenza \\
\hline $75,000,000$ & Worldwide & $1918-1920$ & 1918 flu pandemic & Influenza \\
\hline $2,000,000$ & Worldwide & $1957-1958$ & Asian flu & Influenza \\
\hline $1,000,000$ & Worldwide & $1968-1969$ & Hong Kong flu & Influenza \\
\hline 775 & Asia & $2002-2003$ & SARS & SARS coronavirus \\
\hline 14,286 & Worldwide & 2009 & 2009 flu pandemic & Influenza \\
\hline Incalculable & Worldwide & $1950-$ & Antibiotic resistance & Infectious diseases \\
\hline
\end{tabular}

deaths occur every year attributable to AR, and this number is increasing. The financial costs associated with treating these intractable infections are in the many billions of dollars, and the emotional cost has been enormous (Davies et al. 2014). Indeed, many infected patients in the population may well be treated successfully, but antibiotic overuse and misuse propagates resistance development and further mortality from worsening, untreatable conditions. We have been using antibiotics in ever-increasing amounts for the last half century, and it is estimated that the AR plague may have claimed $>500$ million lives worldwide.

The AR plague has broad sequelae: Domesticated animals such as pets and farm animals also die of infection with AR pathogens. This contributes to the global AR gene pool (Bush et al. 2011). Furthermore, we have little or no notion as to the effects of antibiotics and resistance on the global microbial ecosystem that provides endless services to humans (Colwell 1997). The worldwide economic consequences of AR are difficult to evaluate; meanwhile, antibiotics have not eliminated a single microbial disease.

\section{A BRIEF HISTORICAL PERSPECTIVE}

In all probability, microbial resistance to toxic molecules occurred long before the modern era of antibiotics. Indeed, agents such as arsenicals and mercurials were used for centuries in treating disease even while the role of microbes in causing these afflictions was not recognized. Often, treatment failure was more likely caused by the toxicity of the potion rather than the disease. It is not coincidental that many antibiotic resistance plasmids isolated in the 1950s carried genes for resistance to salts of arsenic and mercury (Silver and Misra 1988). There is also a real possibility that genetically determined resistance was spread during the intense pollution in the late 18th and early 19th centuries, when the environmental microbiomes of the industrial world were exposed to huge amounts of 
toxic organic chemicals. Not everyone lived in Downton Abbey! Respiratory diseases were very common in industrial areas like Manchester, Pittsburgh, and in other countries throughout the world. Currently, many cities in Asia suffer the same problem. What immediate and lasting impacts might this pollution have on human microbiomes?

\section{SOME ANTIMICROBIAL HISTORY}

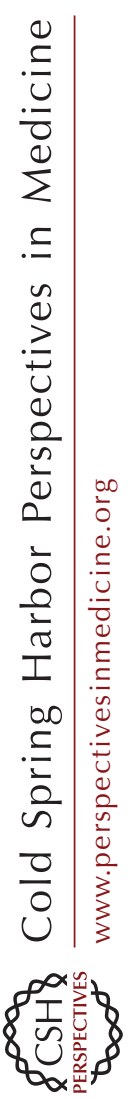

The true antibiotic era began with the discovery of penicillin (a fungal product) by Fleming in the late 1920s, but serious studies did not commence until the 1930s (Abraham and Chain 1988). By the 1930s, most of the common infectious diseases were identified as microbial in origin and specific treatments could be applied. The first significant treatment discovery was that of the sulfonamides, a class of synthetic antimicrobial agents introduced into clinical practice in 1935. Sulfonamides were inexpensive, easily produced in large amounts, and were widely used in different forms and, together with penicillin, played an incredibly important role for the Allied forces in the Second World War preventing many deaths. Winston Churchill was treated successfully for bacterial pneumonia with sulfapyridine; this was obviously of great importance! Sulfonamide resistance was undoubtedly encountered in certain cases but there are few descriptions in the early literature; the biochemical and genetic mechanism(s) involved were not studied at the time. The situation has changed and mechanisms of action and resistance to the sulfonamide drugs have been well characterized (Sköld 2000). For example, antibiotic resistance integrons encoding sulfonamide resistance were unrecognized until the isolation of multiply drug-resistant strains in postwar Japan (Davies 1995). Sulfonamides are still in use today although less frequently.

Trimethoprim is another synthetic agent that was developed in the early 1960s and, like the sulfa drugs, has enjoyed a long life. It is often used in combination with a sulfonamide for the treatment of urinary tract infections, and dual resistance was first identified in 1969. Within the context of this short article, it is worth noting that resistance to sulfa drugs and trimethoprim can occur by mutations in the target pathways or by inheritance of plasmids carrying altered, drug-insensitive variants of the target enzymes (Sköld 2001). Very few examples are required to see that $\mathrm{AR}$ mechanisms are extremely varied and widely distributed.

It is often forgotten that Bacillus strains were studied early on and found to produce some of the first bioactive molecules, of which a number have proven to be useful therapeutics. These included polymyxin (the universal topical treatment) and colistin, currently one of the few drugs available for certain multidrug-resistant Pseudomonas infections. These compounds have been used for more than 80 years, and plasmid-borne colistin resistance has recently been observed to be widespread in China (Liu et al. 2016) (next stop, Europe and the United States). Sadly, there appears to have been little effort devoted to the discovery and development of bioactive compounds from Bacillus sp. and related genera in recent times. For some reason, pharmaceutical companies do not favor peptide drugs. These and other "forgotten" bacterial genera should become more fashionable now that their genome sequences can be scanned for biosynthetic pathways in the search for novel classes of bioactive compounds. Another topic of interest concerns the evolution of antibiotic resistance in the case of Mycobacterium tuberculosis (Mtb). The sole source of resistance to antiTB drugs is by mutation of the target genes and no transferable antibiotic resistance plasmids have been found to encode resistance in Mtb: This pathogen seems to take care of antimicrobials quite nicely without participating in sex (Musser 1995).

\section{THE CHEMICAL DEVELOPMENT OF ANTIBIOTICS}

Since the discovery of antibiotic resistance genes that modify (inactivate) antibiotics, there has been considerable effort to develop, by synthetic chemical methods, compounds that prevent, inhibit, or otherwise avoid antibiotic resistance (Davies 2014). With each new resistance mech- 
anism, we begin a search for blocking agents to restore antibiotic activity and there have been some remarkable successes. This often consists of the removal or modification of functional sites of antibiotic "core" structures to avoid modification or inactivation by resistance enzymes. A good example of this approach is the chemical modification of aminoglycosides to prevent phosphorylation or acetylation of sugar hydroxyl groups or amino groups (Davies 2006). In the case of amikacin, a structural element from a less effective aminoglycoside was added synthetically to kanamycin and prevented specific enzymatic modifications. The discovery of compounds such as amikacin were landmarks, but unfortunately not all resistance modifications can be avoided in this way and "Achilles heels" remain on the modified drugs (Courvalin and Davies 1977). Another example is the chemical modification of $\beta$-lactam antibiotics to prevent hydrolytic cleavage of the $\beta$ lactam ring, which has been successful in the case of the modern $\beta$-lactam antimicrobials. But again, modified $\beta$-lactamase enzymes $(>1000)$ have evolved in concert with the development of new semi-synthetic $\beta$-lactams, and the conflict continues (Bush and Jacoby 2010). The case of the quinolones is especially interesting. When the fluoroquinolones were introduced, it was claimed by some that no resistance modification other than mutation of this new class of completely synthetic antimicrobials would be possible. Little did they know-microbes responded to this challenge successfully by adapting another enzyme for the job, and transferable resistance to the fluoroquinolones is now common in Gram-negative pathogens (Strahilevitz et al. 2009). Resistance is inevitable.

\section{RESISTOMES}

One of the most remarkable environmental findings of recent years is that of antibiotic resistomes: conglomerations of putative resistance genes isolated from a variety of environmental sources (Forsberg et al. 2012). This descriptive term was coined by Wright and his colleagues and confirmed and extended by the characterization of resistomes from many dif- ferent environments (D'Costa et al. 2006). They include soils, ancient caves, and, not surprisingly, gut microbiomes-(putative) antibiotic resistance genes are everywhere. The question is, do these reservoirs play any role in the determination of clinically significant antibiotic resistance? The putative AR genes from resistomes have been shown to be active by gene-expression studies, but this does not establish their natural function. Indeed, the presence of AR genes in bacteria has been shown to influence many other phenotypes. Is it possible that these antibiotic resistance genes have different properties in the wild? Is there any evidence for association with plasmids? To date, the presence of natural resistomes appears to have no causal relationship with the use of antibiotics.

\section{GENE TRANSFER}

Antibiotic resistance might have been less of a problem were it not for the fact that most AR genes are genetically mobile. Resistance transfer factors (R-plasmids) appeared on the environmental/clinical scene in the 1950s in Japan, the United States, and Europe: Where did they originate? The combined interaction of mutation and gene transfer must have been taking place (with respect to resistance development) since eternity. There seems to be endless diversity with rampant gene exchange occurring within related groups of microbes and plasmids that are but one of the transfer mechanisms (Polz et al. 2013). Bacterial gene transfer has become prominent because of the use of antibiotics, and equally powerful selections were likely operating during the period of the industrial revolution (toxic chemicals and poisons). There is still much to be learned about gene transfer mechanisms and origins of AR genes. What is clear is that microbes are able to recombine promiscuously and readily access local gene pools. It is interesting to note that some recent studies of plasmids with strictly environmental roles show that they can be rapidly assembled and disseminated (Xue et al. 2015). Even with the most modern sequence data and analyses of resistance islands, it is not possible to trace the AR genes back to their origins (Ashton et al. 2015). What 
The Whys and Wherefores of Antibiotic Resistance

are natural functions and origins of AR genes? If the resistomes have their supposed function, does one find antibiotic-producing organisms and plasmids in plenitude in resistome environments? There are resistomes in the human gut, but do their resistance phenotypes all relate to antibiotics being ingested? If a person has never been treated with antibiotics such as tetracycline, streptomycin, or chloramphenicol, etc., where did the resistance genes come from?

\section{THE BIG MISTAKE}

The current situation, wherein transferable multidrug resistance exists universally, was an inevitable consequence of the negligent treatment practices used (and to some extent continued) when antimicrobials were first introduced in the 1940s. Their use as therapeutics was generally successful, but there were many senseless practices. For example, using antibiotic fermentation residues (and crude antibiotics) as feed supplements in the beef, chicken, and fish industries have proven to be a contributor to the AR plague. Efforts have been made to control these misuses, but they have only been partly successful in a few countries, and the consequences of the worldwide commercial (nothealth-related) use of antibiotics are now irreversible. Antibiotic production residues should never have been used in agriculture and as food supplements for animals and fish. In retrospect, it seems that everything possible was done to ensure that antimicrobial use was encouraged in as many nonhuman health practices as possible. These actions guaranteed that effective therapeutic applications would be severely limited. Alexander Fleming predicted this outcome but it is unlikely that even he realized what would happen on a global scale.

\section{WHAT SHOULD BE DONE}

1. Strict (legal) control of antibiotic use must be exercised (from compound discovery to the commercial release by the manufacturer) and all remaining residues must be eliminated. Proper hospital practices must be enforced to prevent overuse and disposal of antimicrobials in their active forms. Could antibiotics be destroyed before disposal? Constant monitoring by modern methods is needed within and without. But, how do you punish hospital personnel for noncompliance?

2. Nonhuman use of antibiotics: Be they for prevention, therapy, or for growth promotion, should all be universally banned except for specific agents that are structurally and completely unrelated in mode-of-action to compounds used for humans. Infractions must be disciplined appropriately. Under no circumstances should antibiotic use be permitted other than for human therapy. These measures should have already been adopted internationally.

3. Use of any agent that leads to the development of antibiotic cross-resistant strains, such as triclosan, should be banned, no matter what the proposed use. More research to identify chemicals that cross-select for resistance to antibiotics is essential. The same is true for agents where multiple resistance genes are becoming frequently cotransferred.

4. Should antibiotic use in genetic engineering been permitted? Significant quantities of antibiotics (although very small compared with human and animal use) and AR genes have been used for gene cloning by academia and industry since the early 1970s. The impact of this "misuse" on the advancement of biological science has been enormous and has led, and will lead, to future advances in medicine and biotechnology. The hullabaloo over genetic engineering practices is misplaced, but the extent to which it depends on the use of antibiotic and resistance selection should be considered.

In conclusion, is there reason for optimism for the future of antibiotic therapy? Of course there is, but the only solution is to generate collections of truly novel antibiotics with a narrow spectrum of action that can be combined with synthetic inhibitors of AR function. There is no shortage of potential therapeutic agents in nature; there are many new antibiotics to be dis- 
covered, and current methodology comes nowhere near exhausting searches of natural environments. Creative screening approaches that rely on natural properties such as signaling will lead to a renewable supply of novel compounds. The same can be anticipated with bioinformatic-heterologous expression approaches (Donia and Fischbach 2015). However, the compounds will have short useful lives unless there is strict control of their use. AR is an evolutionary response by microbes that has had drastic consequences for the human race. We need to study the origins of AR and elucidate their "natural" functions. A key component will be to understand how AR diversity is generated as a result of rapid gene transfer and turnover. Finally, it must be recognized that the AR plague was entirely man-made and could/should have been prevented and/or contained by stricter control of the use of antibiotics. Without appropriate compliance of regulations, it is unlikely that the spread of AR will ever be prevented.

\section{ACKNOWLEDGMENTS}

We thank Vivian Miao and the reviewers for helpful comments.

\section{REFERENCES}

Abraham EP, Chain E. 1988. An enzyme from bacteria able to destroy penicillin. 1940. Rev Infect Dis 10: 677-678.

Ashton PM, Satheesh N, Dallman T, Rubino S, Rabsch W, Mwaigwisya S, Wain J, O’Grady J. 2015. MinION nanopore sequencing identifies the position and structure of a bacterial antibiotic resistance island. Nat Biotechnol 33: 296-300.

Bush K, Jacoby GA. 2010. Updated functional classification of $\beta$-lactamases. Antimicrob Agents Chemother 54: 969976.

Bush K, Courvalin P, Dantas G, Davies J, Eisenstein B, Huovinen P, Jacoby GA, Kishony R, Kreiswirth BN, Kutter E, et al. 2011. Tackling antibiotic resistance. Nat Rev Microbiol 9: 894-896.

Colwell RR. 1997. Microbial diversity: The importance of exploration and conservation. J Ind Microbiol Biotechnol 18: $302-307$.
Courvalin P, Davies J. 1977. Plasmid mediated aminoglycoside phosphotransferase of broad substrate range that phosphorylates amikacin. Antimicrob Agents Chemother 11: 619-624.

D'Costa VM, McGrann KM, Hughes DW, Wright GD. 2006. Sampling the antibiotic resistome. Science 311: 374-377.

Davies J. 1995. Vicious circles: Looking back on resistance plasmids. Genetics 139: 1465-1468.

Davies JE. 2006. Aminoglycosides: Ancient and modern. J Antibiot (Tokyo) 59: 529-532.

Davies J. 2014. The origin and evolution of antibiotics. In Antimicrobials, pp. 3-10. Springer, Berlin.

Davies J, Davies D. 2010. Origins and evolution of antibiotic resistance. Microbiol Mol Biol Rev 74: 417-433.

Davies J, Smith DI. 1978. Plasmid-determined resistance to antimicrobial agents. Annu Rev Microbiol 3: 469-518.

Davies S, Grant J, Catchpole M. 2014. The drugs don't work: A global threat. Viking, New York.

Donia MS, Fischbach MA. 2015. HUMAN MICROBIOTA. Small molecules from the human microbiota. Science 349: 1254766.

Forsberg KJ, Reyes A, Wang B, Selleck EM, Sommer MO, Dantas G. 2012. The shared antibiotic resistome of soil bacteria and human pathogens. Science 337: 1107-1111.

Liu YY, Wang Y, Walsh TR, Yi LX, Zhang R, Spencer J, Doi Y, Tian G, Dong B, Huang X, et al. 2016. Emergence of plasmid-mediated colistin resistance mechanism MCR1 in animals and human beings in China: A microbiological and molecular biology study. Lancet Infect Dis 16: $161-168$.

Musser JM. 1995. Antimicrobial agent resistance in mycobacteria: Molecular genetic insights. Clin Microbiol Rev 8: 496-514.

Polz MF, Alm EJ, Hanage WP. 2013. Horizontal gene transfer and the evolution of bacterial and archaeal population structure. Trends Genet 29: 170-175.

Silver S, Misra TK. 1988. Plasmid-mediated heavy metal resistances. Annu Rev Microbiol 42: 717-743.

Sköld O. 2000. Sulfonamide resistance: Mechanisms and trends. Drug Resist Updat 3: 155-160.

Sköld O. 2001. Resistance to trimethoprim and sulfonamides. Vet Res 32: 261-273.

Strahilevitz J, Jacoby GA, Hooper DC, Robicsek A. 2009. Plasmid-mediated quinolone resistance: A multifaceted threat. Clin Microbiol Rev 22: 664-689.

Wright GD. 2011. Molecular mechanisms of antibiotic resistance. Chem Commun 47: 4055-4061.

Xue H, Cordero OX, Camas FM, Trimble W, Meyer F, Guglielmini J, Rocha EP, Polz MF. 2015. Eco-evolutionary dynamics of episomes among ecologically cohesive bacterial populations. MBio 6: $1-10$. 


\section{$\&_{\mathrm{CSH}}^{\infty} \&$ Cold Spring Harbor

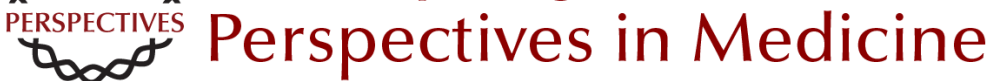

\section{The Whys and Wherefores of Antibiotic Resistance}

Cameron R. Strachan and Julian Davies

Cold Spring Harb Perspect Med 2017; doi: 10.1101/cshperspect.a025171 originally published online October 28, 2016

\section{Subject Collection Antibiotics and Antibiotic Resistance}

Fosfomycin: Mechanism and Resistance Lynn L. Silver

Pleuromutilins: Potent Drugs for Resistant Bugs

--Mode of Action and Resistance Susanne Paukner and Rosemarie Riedl

Appropriate Targets for Antibacterial Drugs Lynn L. Silver

Lincosamides, Streptogramins, Phenicols, and Pleuromutilins: Mode of Action and Mechanisms of Resistance

Stefan Schwarz, Jianzhong Shen, Kristina Kadlec, et al.

Resistance to Macrolide Antibiotics in Public Health Pathogens Corey Fyfe, Trudy H. Grossman, Kathy Kerstein, et al.

Bacterial Protein Synthesis as a Target for

Antibiotic Inhibition Stefan Arenz and Daniel N. Wilson

Antibacterial Antifolates: From Development through Resistance to the Next Generation Alexavier Estrada, Dennis L. Wright and Amy C. Anderson

Antibacterial Drug Discovery Targeting the Lipopolysaccharide Biosynthetic Enzyme LpxC Alice L. Erwin
The Whys and Wherefores of Antibiotic

Resistance

Cameron R. Strachan and Julian Davies

$\beta$-Lactamases: A Focus on Current Challenges Robert A. Bonomo

Approved Glycopeptide Antibacterial Drugs: Mechanism of Action and Resistance Daina Zeng, Dmitri Debabov, Theresa L. Hartsell, et al.

Mechanism of Action and Resistance to Daptomycin in Staphylococcus aureus and Enterococci William R. Miller, Arnold S. Bayer and Cesar A. Arias

Polymyxin: Alternative Mechanisms of Action and Resistance Michael J. Trimble, Patrik Mlynárcik, Milan Kolár, et al.

Topoisomerase Inhibitors: Fluoroquinolone Mechanisms of Action and Resistance David C. Hooper and George A. Jacoby

$\beta$-Lactams and $\beta$-Lactamase Inhibitors: An Overview Karen Bush and Patricia A. Bradford

Rifamycins, Alone and in Combination David M. Rothstein

For additional articles in this collection, see http://perspectivesinmedicine.cshlp.org/cgi/collection/ 